\title{
PRODUKSI MASSAL BENIH IKAN HIAS BOTIA (Chromobotia macracanthus) MELALUI PENDEKATAN PADAT TEBAR DAN KETINGGIAN AIR MEDIA PEMELIHARAAN
}

\author{
Agus Priyadi, Asep Permana, dan Nurhidayat \\ Balai Penelitian dan Pengembangan Budidaya Ikan Hias \\ Jl. Perikanan No. 13, Pancoran Mas, Depok 16436 \\ E-mail: publikasi.bppbih@gmail.com
}

(Naskah diterima: 5 April 2012; Disetujui publikasi: 25 Maret 2013)

\begin{abstract}
ABSTRAK
Ikan botia (Chromobotia macracanthus) merupakan ikan hias asli dari perairan Sumatera dan Kalimantan yang memiliki potensi besar sebagai komoditas ekspor karena bentuk yang unik dan mempunyai warna yang indah. Permasalahan utama sampai saat ini adalah masih rendahnya sintasan larva hingga benih pada tahap pendederan (umur dua bulan). Penelitian ini dilakukan untuk mengetahui respons tingkat padat tebar larva $(5,10$, dan 15 ekor/L) pada dua tingkat ketinggian air media pemeliharaan (16 dan $32 \mathrm{~cm}$ ) dengan empat ulangan. Wadah pemeliharaan berupa akuarium ukuran $80 \mathrm{~cm} \times 40 \mathrm{~cm} \times 40 \mathrm{~cm}$ dengan sistem resirkulasi. Selama pemeliharaan, larva diberi pakan berupa nauplii Artemia di bulan pertama, sedangkan di bulan kedua diberi pakan nauplii Artemia dan bloodworm (cacing darah/larva Chironomus sp.) beku, serta diberikan secara sekenyangnya (ad satiation). Parameter yang diamati meliputi sintasan, pertumbuhan (pertambahan panjang total dan bobot mutlak), dan data kualitas air. Data yang diperoleh akan diolah dan dianalisis secara statistik menggunakan program SPSS versi 17.0. Hasil penelitian memperlihatkan bahwa padat tebar dan ketinggian air media pemeliharaan larva hingga benih sampai umur 2 bulan berpengaruh nyata terhadap sintasan, akan tetapi tidak berpengaruh nyata terhadap pertambahan panjang total dan bobot mutlak. Perlakuan dengan padat tebar 15 ekor/L dan ketinggian air media pemeliharaan $16 \mathrm{~cm}$ dapat direkomendasikan untuk pemeliharaan larva hingga benih sampai ukuran $0,5 \mathrm{~cm}$.
\end{abstract}

KATA KUNCI: produksi massal, ketinggian air, kepadatan, ikan botia

ABSTRACT: Clown loach (Chromobotia macracanthus) mass production improvement through stocking density and water level approach. By: Agus Priyadi, Asep Permana, and Nurhidayat

Clown loach or Chromobotia macracanthus which originated from Sumatra and Borneo Island has a big potential as an export commodities because of its unique and beautiful color. But, the problem still exists until now, particularly the problem of survival rate in first rearing phase (until reach 2 month of age). The objective of this research was to determine the respond of different stocking density level of larval rearing $(5,10$, and 15 individual/L) in two different water level $(16$ and $32 \mathrm{~cm})$, replicated four times in first rearing phase, in order to increase the survival rate and by consequence will support the mass production of this fish. Fishes were reared in aquarium $80 \mathrm{~cm} \times 40 \mathrm{~cm} \times 40 \mathrm{~cm}$ by recirculation system. During the experimental period, larvae were fed by Artemia (until reach 1 month of age) and using the combination between bloodworm and Artemia (for the next 1 month). Survival rate, growth rate and water quality are the parameters observed. Data will be analyzed 
using SPSS version 17.0. According to the result, we can assume that different stocking density and water level during two months period rearing gave a significant effect to the survival rate but not significantly gave an effect to the total length and total weight. Treatment with 15 individu/L and water level $16 \mathrm{~cm}$ can be recommended for larval rearing of clown loach until reach $0.5 \mathrm{~cm}$ of total length.

\section{KEYWORDS: mass production, water level, stocking density, clown loach}

\section{PENDAHULUAN}

Ikan botia (Chromobotia macracanthus) merupakan ikan hias asli dari perairan Sumatera dan Kalimantan yang memiliki potensi besar sebagai komoditas ekspor karena mempunyai bentuk yang unik dan warna yang indah. Menurut informasi dari beberapa eksportir ikan hias di Jabodetabek bahwa ikan ini merupakan primadona ikan hias air tawar yang dapat dijual pada ukuran $5,0 \mathrm{~cm}$ (2 inci) dengan harga 0,65-1,00 USD per ekor dan memiliki pangsa pasar yang luas, baik dalam maupun luar negeri. Hingga saat ini, semua ikan botia yang dijual di pasar dunia merupakan hasil tangkapan dari alam. Penangkapan secara berlebihan yang terus-menerus dilakukan dikhawatirkan akan mengancam kelestarian ikan botia tersebut. Hal ini didukung dengan adanya regulasi pasar Eropa yang merekomendasikan produk ekspor ikan hias yang nantinya harus berasal dari hasil budidaya.

Kerja sama penelitian yang dilakukan antara Balai Penelitian dan Pengembangan Budidaya Ikan Hias dengan IRD-Perancis telah berhasil memijahkan ikan botia sepanjang tahun di luar habitatnya. Kegiatan ini boleh dikatakan cukup berhasil dengan indikasinya yaitu produksi larva umur dua hari makan nauplii Artemia (umur 7 hari) sebanyak 114.000 ekor di tahun 2009 dan 165.000 ekor di tahun 2010. Sedangkan sintasan dari larva hingga menjadi benih ukuran $4,2-5,0 \mathrm{~cm}$ ( $1,75-2$ inci) dan benih siap untuk dipasarkan sekitar 13\% di tahun 2009 dan 24,2\% di tahun 2010 .

Produksi larva yang dihasilkan masih jauh dari harapan, hal ini karena masih rendahnya sintasan larva hingga benih selama dua bulan pemeliharaan pada tahap pendederan. Untuk dugaan sementara, ketinggian air media pemeliharaan yang selama ini dilakukan masih terlalu tinggi yaitu $32 \mathrm{~cm}$. Padahal dalam pemeliharaan larva untuk hampir semua jenis ikan biasanya ketinggian air media berkisar antara $10-20 \mathrm{~cm}$. Hal ini sejalan dengan Kristikareni (2009), bahwa ketinggian air media $16 \mathrm{~cm}$ yang digunakan dalam penelitiannya memperlihatkan sintasan larva botia mencapai $95 \%$.

Hasil penelitian tentang pemeliharaan larva botia dengan berbagai tingkat kepadatan 15 , 20, 25, 30, dan 35 ekor/L dalam akuarium bervolume 5 liter dengan sistem resirkulasi, tidak memperlihatkan perbedaan yang nyata antar perlakuan selama 40 hari (Kristikareni, 2009). Akan tetapi setelah diaplikasikan pada skala wadah yang lebih besar secara berulangulang selama ini, yaitu menggunakan akuarium volume 100 liter dengan kepadatan 15 ekor/L pada ketinggian air media $32 \mathrm{~cm}$ dalam sistem resirkulasi ternyata menghasilkan sintasan yang rendah. Berdasarkan dari hasil evaluasi tersebut diduga bahwa adanya perbedaan tingkat ketinggian air media pemeliharaan. Effendi (2004) menyatakan bahwa larva adalah anak ikan yang berukuran sangat kecil, memiliki morfologi, anatomi, dan fisiologi yang sederhana, sifatnya sensitif, lemah, dan mudah terganggu baik secara fisik, biologis maupun kimia. Pada ketinggian air media yang lebih tinggi, larva akan mengeluarkan energi lebih banyak di mana untuk menahan tekanan air dan pada saat mengejar mangsa, jika dibandingkan pemeliharaan larva pada tingkat ketinggian air media yang lebih rendah.

Penelitian ini dilakukan dengan tujuan untuk melihat pengaruh tingkat padat tebar larva botia dan tingkat ketinggian air media pemeliharaan terhadap sintasan, pertumbuhan, sebaran ukuran ikan dan diharapkan dapat menjawab permasalahan yang ada selama ini terutama pada tahap pendederan (dua bulan pemeliharaan).

\section{BAHAN DAN METODE}

Penelitian dilakukan di Balai Penelitian dan Pengembangan Budidaya Ikan Hias pada bulan Mei-Juni 2011 . Wadah penelitian berupa akuarium ukuran $80 \mathrm{~cm} \times 40 \mathrm{~cm} \times 40 \mathrm{~cm}$ dengan sistem resirkulasi sebanyak 24 buah. Ikan uji yang digunakan yaitu larva botia umur 
7 hari (baru dua hari makan nauplii Artemia) dengan panjang rata-rata $5,7 \pm 0,3 \mathrm{~mm}$ dan bobot rata-rata $1,9 \pm 0,3 \mathrm{mg}$ dari hasil pemijahan sendiri sebanyak 18.000 ekor. Selama penelitian larva botia diberi pakan berupa nauplii Artemia pada satu bulan pertama dan di bulan kedua diberi pakan nauplii Artemia dan bloodworm (cacing darah/larva Chironomus sp.) beku secara sekenyangnya (ad satiation) dengan frekuensi lima kali per hari pukul 08.00, 11.00, 14.00, 17.00, dan 20.00.

Penelitian ini menggunakan rancangan faktorial $3 \times 2$ di mana perlakuannya terdiri atas faktor padat tebar larva (5, 10, dan 15 ekor/L) dan faktor ketinggian air media pemeliharaan (16 dan $32 \mathrm{~cm}$ ) dengan masing-masing empat ulangan.

Pengambilan data (sampling ikan uji) dilakukan sebulan sekali terhadap sintasan, pertambahan panjang total, bobot mutlak, dan kualitas air. Untuk data pertambahan panjang total dan bobot mutlak diambil sebanyak $10 \%$ dari jumlah total setiap akuarium. Sedangkan untuk sebaran ukuran ikan dilihat pada akhir penelitian. Parameter yang diamati meliputi:

Sintasan, dengan perhitungan menggunakan rumus berdasarkan Effendie (1979):

$$
\mathrm{S}=\mathrm{Nt} / \mathrm{No} \times 100 \%
$$

di mana:

$\mathrm{S}=$ Persentase sintasan (\%)

$\mathrm{Nt}=$ Jumlah ikan akhir penelitian (ekor)

No = Jumlah ikan awal penelitian (ekor)
Pertambahan panjang total, dengan perhitungan menggunakan rumus berdasarkan Effendie (1979):

$$
\mathrm{L}=\mathrm{Lt}-\mathrm{Lo}
$$

di mana:

$\mathrm{L}=$ Panjang total $(\mathrm{cm})$

$\mathrm{Lt}=$ Panjang rata-rata individu akhir penelitian (cm)

Lo $=$ Panjang rata-rata awal penelitian $(\mathrm{cm})$

Pertumbuhan bobot mutlak, dengan perhitungan menggunakan rumus berdasarkan Weatherley (1972):

$$
\mathrm{Wm}=\mathrm{Wt}-\mathrm{Wo}
$$

di mana:

Wm $=$ Pertumbuhan mutlak $(\mathrm{g})$

$\mathrm{Wt}=$ Bobot rata-rata individu akhir penelitian (g)

Wo = Bobot rata-rata awal penelitian (g)

Lama penelitian dua bulan. Data yang diperoleh akan diolah dan dianalisis secara statistik menggunakan program SPSS versi 17.0.

\section{HASIL DAN BAHASAN}

\section{Sintasan}

Nilai sintasan, pertambahan panjang total dan bobot mutlak benih ikan botia pada bulan pertama tertera pada Tabel 1.

Dilihat dari Tabel 1, sintasan tertinggi dihasilkan oleh perlakuan padat tebar larva

Tabel 1. Sintasan, pertambahan panjang total dan bobot mutlak benih ikan botia di bulan pertama Table 1. Survival rate, length and weight gain of clown loach fish fry until the first month

\begin{tabular}{ccccc}
\hline $\begin{array}{c}\text { Padat tebar } \\
\text { (ekor/L) } \\
\text { Stocking density } \\
\text { (Iarvae/L) }\end{array}$ & $\begin{array}{c}\text { Ketinggian air } \\
\text { Water high level } \\
(\mathbf{c m})\end{array}$ & $\begin{array}{c}\text { Sintasan } \\
\text { Survival rate } \\
\mathbf{( \% )}\end{array}$ & $\begin{array}{c}\text { Pertambahan } \\
\text { panjang total } \\
\text { Length gain } \\
(\mathbf{c m})\end{array}$ & $\begin{array}{c}\text { Bobot mut } \\
\text { Weight gain } \\
(\mathbf{g})\end{array}$ \\
\hline \multirow{2}{*}{5} & 16 & $90.5 \pm 6.78^{\mathrm{a}}$ & $0.4 \pm 0.02^{\mathrm{a}}$ & $0.0106 \pm 0.0023^{\mathrm{a}}$ \\
& 32 & $83.5 \pm 6.79^{\mathrm{ab}}$ & $0.4 \pm 0.02^{\mathrm{a}}$ & $0.0104 \pm 0.0016^{\mathrm{a}}$ \\
10 & 16 & $86.7 \pm 2.23^{\mathrm{a}}$ & $0.4 \pm 0.05^{\mathrm{a}}$ & $0.0116 \pm 0.0049^{\mathrm{a}}$ \\
& 32 & $78.5 \pm 13.33^{\mathrm{ab}}$ & $0.5 \pm 0.12^{\mathrm{a}}$ & $0.0152 \pm 0.0059^{\mathrm{a}}$ \\
15 & 16 & $70.67 \pm 15.15^{\mathrm{ab}}$ & $0.5 \pm 0.10^{\mathrm{a}}$ & $0.0132 \pm 0.0042^{\mathrm{a}}$ \\
& 32 & $58.67 \pm 11.81^{\mathrm{b}}$ & $0.5 \pm 0.15^{\mathrm{a}}$ & $0.0136 \pm 0.0130^{\mathrm{a}}$ \\
\hline
\end{tabular}

Keterangan (Note):

Notasi huruf yang sama pada kolom yang sama menunjukkan tidak berbeda nyata $(P>0,05)($ The same alphabet on the same column means not significantly different $(P>0,05))$ 
5 ekor/L pada ketinggian air media $16 \mathrm{~cm}$ dengan nilai $90,5 \pm 6,78 \%$ dan sintasan terendah pada perlakuan padat tebar larva 15 ekor/L pada ketinggian air media $16 \mathrm{~cm}$ sebesar $70,67 \pm 15,15 \%$. Berdasarkan uji statistik, sintasan pada kelima perlakuan tersebut tidak berbeda nyata pada $P>0,05$. Sedangkan pada perlakuan padat tebar larva 15 ekor/L pada ketinggian air media $32 \mathrm{~cm}$ merupakan perlakuan yang menghasilkan sintasan terendah dengan nilai sebesar $58,67 \pm 11,81 \%$. Berdasarkan uji statistik berbeda nyata pada $\mathrm{P}<0,05$ dengan perlakuan padat tebar larva 5 ekor/L pada ketinggian air media $16 \mathrm{~cm}$ dan perlakuan padat tebar larva 10 ekor/L pada ketinggian air media $16 \mathrm{~cm}$ akan tetapi tidak berbeda nyata dengan perlakuan padat tebar larva 5 ekor/L pada ketinggian air media 32 $\mathrm{cm}$, perlakuan padat tebar larva 10 ekor/L pada ketinggian air media $32 \mathrm{~cm}$ dan perlakuan padat tebar larva 15 ekor/L pada ketinggian air media $16 \mathrm{~cm}$.

Melihat dari data sintasan pada pemeliharaan larva hingga benih di bulan pertama, untuk semua padat tebar pada dua ketinggian air media menunjukkan adanya peningkatan dibandingkan sintasan pada skala produksi yang selama ini dilakukan yaitu $56 \%$. Peningkatan paling tinggi diperoleh pada perlakuan ketinggian air media $16 \mathrm{~cm}$ untuk semua padat tebar dibandingkan pada ketinggian air media $32 \mathrm{~cm}$. Perbedaan ini dikarenakan pada ketinggian air media $16 \mathrm{~cm}$ mempunyai ruang gerak lebih sempit dan ketinggian air lebih dangkal dibandingkan ketinggian air media $32 \mathrm{~cm}$. Menurut Odum (1993), hubungan antara ruang gerak dan ketinggian air pada pemeliharaan larva adalah bahwa ikan belia pada stadia larva memiliki sifat planktonis sehingga dalam usaha pencarian makannya akan lebih efektif pada ruang dan ketinggian air yang kecil dibandingkan yang besar. Efektivitasnya ini bisa dilihat dari energi yang digunakan dalam mencari pakan pada ruang gerak dan ketinggian air yang kecil akan lebih sedikit dibandingkan pada ruang gerak dan ketinggian air yang lebih besar.

Dalam mencari pakan, larva perlu memburu mangsa dengan berenang horisontal atau vertikal. Hal ini tentunya memerlukan energi lebih besar jika ruang gerak tempat hidupnya lebih besar. Ditambah lagi adanya tekanan air yang lebih besar pada media pemeliharaan dengan ketinggian lebih tinggi, tentunya akan menambah energi yang dikeluarkan oleh larva pada saat berburu pakan. Menurut Helfman et al. (1997) tekanan hidrostatik bertambah secara konstan seiring dengan bertambahnya kedalaman atau ketinggian air. Setiap kedalaman $10 \mathrm{~m}$ tekanan hidrostatik bertambah sebesar $1 \mathrm{~atm}$ yang setara dengan $1,03 \mathrm{~kg} /$ $\mathrm{cm}^{2}$ atau $14,7 \mathrm{lbs} / \mathrm{in}^{2}$, artinya tekanan hidrostatik yang dialami ikan tersebut sama pada seluruh bagian tubuhnya. Perbedaan ketinggian air media antara ketinggian 16 dan $32 \mathrm{~cm}$ hanyalah $16 \mathrm{~cm}$, akan tetapi ada sedikit pengaruh buat larva dalam hal energi yang dikeluarkan pada saat memburu pakan walaupun hal ini perlu penelitian lebih lanjut.

Jika dilihat dari efektivitas pada media air pemeliharaan dengan ketinggian $16 \mathrm{~cm}$ dibandingkan $32 \mathrm{~cm}$ terjadi pada minggu pertama hingga minggu kedua penelitian. Pada saat itu, larva botia berenang dan geraknya masih sangat lambat tidak seperti larva-larva ikan pada umumnya. Selain itu, memiliki sifat atau tingkah laku suka menyebar dan menempel pada semua permukaan akuarium. Sehingga pada saat diberi pakan berupa nauplii Artemia yang mempunyai sifatnya atau tingkah laku akan tenggelam secara perlahan ke dasar dan mengumpul, jadi tidak semua larva botia mendapatkan pakan. Larva botia yang berhasil hidup dan tumbuh cepat besar biasanya yang berada di dasar akuarium yang memiliki akses lebih besar untuk mendapatkan pakan. Untuk itulah kondisi ruang gerak yang kecil dan ketinggian air media yang rendah akan memungkinkan lebih efektif. Hal ini terlihat dengan lebih banyaknya kematian larva botia pada perlakuan ketinggian air media $32 \mathrm{~cm}$ dibandingkan pada perlakuan ketinggian air media $16 \mathrm{~cm}$ untuk semua padat tebar pada minggu pertama hingga minggu kedua penelitian. Pada minggu ketiga sampai minggu berikutnya seiring perkembangan larva yang semakin sempurna seperti ikan dewasanya. Selain itu, memperlihatkan kondisinya juga semakin kuat dan tingkah laku (sifatnya) akan berubah menjadi benih botia yang selalu aktif berenang dan selalu bergerombol pada saat tidak diberi pakan maupun waktu diberi pakan sehingga pada saat diberi pakan maka semua benih akan berpeluang untuk mendapatkan pakan lebih besar.

Adapun kecenderungan dari nilai sintasan yang terjadi di bulan pertama menunjukkan penurunan seiring meningkatnya padat tebar pada semua tingkat ketinggian air media. Hal ini dikarenakan semakin tingginya padat tebar 
ikan maka akan mempengaruhi kesempatan larva dalam memanfaatkan pakan, oksigen, dan ruang (North et al., 2006). Oleh karena itu, penentuan padat tebar yang tepat merupakan salah satu variabel yang sangat penting dalam bidang budidaya karena akan berpengaruh secara langsung terhadap sintasan, pertumbuhan, tingkah laku, kesehatan, dan kualitas air (Rowland et al., 2006).

Nilai sintasan, pertumbuhan panjang total, dan bobot mutlak benih ikan botia pada bulan kedua tertera pada Tabel 2 .

Nilai sintasan pada bulan kedua ini didapat dengan tetap berpatokan pada nilai padat tebar awal dari percobaan. Dilihat dari Tabel 2 , sintasan tertinggi dihasilkan oleh perlakuan padat tebar larva 5 ekor/L dengan ketinggian

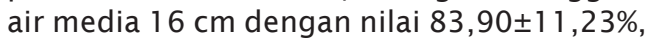
sintasan pada keempat perlakuan tersebut memperlihatkan tidak berbeda nyata satu sama lain. Perlakuan padat tebar larva 15 ekor/L dengan ketinggian air media $32 \mathrm{~cm}$ dan perlakuan padat tebar larva 10 ekor/L dengan ketinggian air media $32 \mathrm{~cm}$ merupakan perlakuan yang menghasilkan sintasan terendah

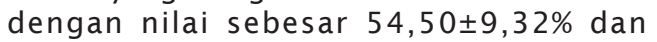
$51,50 \pm 5,55 \%$. Sintasan pada kedua perlakuan ini berbeda nyata dengan perlakuan padat tebar larva 5 ekor/L dengan ketinggian air media $16 \mathrm{~cm}$ akan tetapi tidak berbeda nyata dengan perlakuan padat tebar larva 5 ekor/L dengan ketinggian air media $32 \mathrm{~cm}$, perlakuan padat tebar larva 10 ekor/L dengan ketinggian air media $16 \mathrm{~cm}$ dan perlakuan padat tebar larva 15 ekor/L dengan ketinggian air media $16 \mathrm{~cm}$.

Dari data di atas terlihat jelas bahwa sintasan semakin menurun sejalan dengan bertambahnya padat tebar ikan. Sintasan secara berturut-turut dari tertinggi hingga terendah dihasilkan oleh perlakuan ketinggian air media $16 \mathrm{~cm}$ kemudian diikuti perlakuan ketinggian air media $32 \mathrm{~cm}$. Performansi ini berlaku pada seluruh padat tebar larva 5, 10, dan 15 ekor/L.

Dilihat dari data sintasan pada pemeliharaan larva sampai di bulan kedua, untuk semua padat tebar pada dua ketinggian air media menunjukkan adanya penurunan dibandingkan sintasan pada pemeliharaan larva di bulan pertama. Memasuki pemeliharaan di bulan kedua, stadia larva sudah menjadi benih di mana kondisinya sudah relatif lebih kuat dibandingkan stadia larva. Dugaan awal pada pemeliharaan di bulan kedua ini akan sedikit terjadi kematian ikan, akan tetapi ternyata kematian ikan tetap saja terjadi dan nilainya cukup besar.

Pada pemeliharaan di bulan kedua, sudah ada perubahan pakan dari nauplii Artemia menjadi kombinasi antara nauplii Artemia dan bloodworm (cacing darah/larva Chironomus sp.) beku. Ternyata dengan adanya perubahan jenis pakan ini menyebabkan munculnya variasi ukuran ikan pada semua perlakuan (Tabel 2). Variasi ukuran ini diakibatkan pada

Tabel 2. Sintasan, pertambahan panjang total dan bobot mutlak benih ikan botia pada bulan kedua

Table 2. Survival rate, length, and weight gain of clown loach fish fry until second month

\begin{tabular}{ccccc}
\hline $\begin{array}{c}\text { Padat tebar } \\
\text { (ekor/L) } \\
\begin{array}{c}\text { Stocking density } \\
\text { (larvae/L) }\end{array}\end{array}$ & $\begin{array}{c}\text { Ketinggian air } \\
\text { Water high level } \\
(\mathbf{c m})\end{array}$ & $\begin{array}{c}\text { Sintasan } \\
\text { Survival rate } \\
\mathbf{( \% )}\end{array}$ & $\begin{array}{c}\text { Pertambahan } \\
\text { panjang total } \\
\text { Length gain } \\
(\mathbf{c m})\end{array}$ & $\begin{array}{c}\text { Bobot mutlak } \\
\text { Weight gain } \\
(\mathbf{g})\end{array}$ \\
\hline \multirow{2}{*}{5} & 16 & $83.90 \pm 11.23^{\mathrm{a}}$ & $0.5 \pm 0.05^{\mathrm{a}}$ & $0.0194 \pm 0.0017^{\mathrm{a}}$ \\
& 32 & $75.60 \pm 13.57^{\mathrm{ab}}$ & $0.5 \pm 0.07^{\mathrm{a}}$ & $0.0204 \pm 0.0029^{\mathrm{a}}$ \\
10 & 16 & $65.27 \pm 13.92^{\mathrm{ab}}$ & $0.5 \pm 0.04^{\mathrm{a}}$ & $0.0190 \pm 0.0034^{\mathrm{a}}$ \\
& 32 & $51.50 \pm 5.55^{\mathrm{b}}$ & $0.6 \pm 0.14^{\mathrm{a}}$ & $0.0343 \pm 0.0161^{\mathrm{a}}$ \\
15 & 16 & $63.33 \pm 7.95^{\mathrm{ab}}$ & $0.6 \pm 0.05^{\mathrm{a}}$ & $0.0193 \pm 0.0039^{\mathrm{a}}$ \\
& 32 & $54.50 \pm 9.32^{\mathrm{b}}$ & $0.7 \pm 0.03^{\mathrm{a}}$ & $0.0332 \pm 0.0323^{\mathrm{a}}$ \\
\hline
\end{tabular}

Keterangan (Note):

Notasi huruf yang sama pada kolom yang sama menunjukkan tidak berbeda nyata $(\mathrm{P}>0,05)($ The same alphabet on the same column means not significantly different $(P>0,05))$ 
saat awal perubahan pakan menjadi kombinasi nauplii Artemia dan bloodworm beku, ternyata tidak semua ikan sukses mengikuti perubahan ini. Ikan yang berhasil makan bloodworm beku akan mengalami pertumbuhan yang lebih cepat dibandingkan ikan yang lambat dalam keberhasilannya memakan bloodworm (cacing darah/larva Chironomus sp.) beku walaupun tetap dapat pakan nauplii Artemia. Hal ini sesuai pendapat Huet (1994) yang menyatakan bahwa kualitas pakan, umur, serta kemampuan memanfaatkan pakan inilah yang kemudian akan memengaruhi performansi pertumbuhan benih.

Adanya variasi ukuran menyebabkan efek lanjutan yaitu adanya kompetisi dalam mendapatkan pakan antara ikan ukuran kecil, sedang, dan besar. Variasi ukuran ikan ini juga diduga menyebabkan adanya hirarki sosial diantara ikan tersebut di mana ikan ukuran besar cenderung lebih dominan mendapatkan pakan kemudian diikuti ikan ukuran sedang dan terakhir ikan ukuran kecil. Paspatis et al. (1999) yang menyatakan bahwa pengaruh dari hirarki sosial terhadap perilaku makan ikan ditemukan pada pemeliharaan ikan Atlantic salmon (Salmo salar) dan Arctic charr (Salvelinus alpines).

Akibat dari kompetisi dan hirarki sosial ini akan muncul masalah kesehatan di mana ikan ukuran kecil cenderung lebih kurus, lemah dan warnanya pudar dibandingkan ikan ukuran sedang dan besar. Hal ini didukung oleh pernyataan Wedemeyer (1996), masalah kesehatan dan kondisi stres yang kronis merupakan hasil dari adanya dominasi sosial yang terjadi pada hubungan interaksi di antara ikan, dan ini sering terjadi pada sistem budidaya yang intensif, di mana ikan-ikan yang subordinat (cenderung lemah) memiliki akses yang sangat sedikit untuk mengambil pakan dan cenderung tumbuh lebih lambat, hal ini dikarenakan kalori energi yang dihasilkan sedikit sebagai akibat dari kondisi stres yang kronis.

Jika kondisi ini dibiarkan terus menerus maka akan terjadi kematian. Jadi kasus kematian ikan yang terjadi pada pemeliharaan di bulan kedua lebih disebabkan adanya kompetisi dan hirarki sosial akibat dari variasi ukuran setelah terjadi perubahan jenis pakan dari nauplii Artemia ke kombinasi nauplii Artemia dan bloodworm beku. Kasus kematian ini terjadi pada semua perlakuan sehingga kecenderungan penurunan sintasannya hampir sama seperti pada pemeliharaan di bulan pertama. Di mana nilai sintasan pada perlakuan ketinggian air media $16 \mathrm{~cm}$ lebih besar dibandingkan perlakuan ketinggian air media $32 \mathrm{~cm}$ untuk semua padat tebar.

Adanya perubahan pakan dari nauplii Artemia di bulan pertama menjadi kombinasi nauplii Artemia dengan bloodworm beku pada pemeliharaan di bulan kedua ternyata menyebabkan adanya variasi ukuran ikan. Variasi ukuran yang terjadi pada pemeliharaan di bulan kedua ini, persentasenya tertera pada Tabel 3.

Untuk semua perlakuan padat tebar pada ketinggian air media $16 \mathrm{~cm}$ variasinya lebih rendah dibandingkan ketinggian air media $32 \mathrm{~cm}$. Pada perlakuan ketinggian air media $16 \mathrm{~cm}$ variasi ukuran didominasi oleh ukuran kecil (small) dan sedang (medium) sementara ukuran besar (large) hanya sedikit. Sedangkan pada perlakuan ketinggian air media $32 \mathrm{~cm}$ variasi ukuran lebih tinggi. Hal ini dikarena-

Tabel 3. Variasi ukuran benih ikan botia pada tiap perlakuan di bulan kedua

Table 3. Size variation of clown loach fish fry every treatment at second month

\begin{tabular}{cccc}
\hline \multirow{2}{*}{$\begin{array}{c}\text { Perlakuan } \\
\text { Treatments }\end{array}$} & \multicolumn{3}{c}{ Variasi ukuran (Size variation) (\%) } \\
\cline { 2 - 4 } & $\begin{array}{c}\text { Kecil (Small) } \\
\mathbf{0 . 7 - 0 . 9} \mathbf{~ c m}\end{array}$ & $\begin{array}{c}\text { Sedang (Medium) } \\
\mathbf{1 . 0 - 1 . 2 ~ c m ~}\end{array}$ & $\begin{array}{c}\text { Besar (Large) } \\
\mathbf{1 . 3 - 1 . 5 ~ c m ~}\end{array}$ \\
\hline $\mathbf{5 . 1 6}$ & 72.32 & 26.75 & 0.93 \\
$\mathbf{5 . 3 2}$ & 50.20 & 16.15 & 33.65 \\
$\mathbf{1 0 . 1 6}$ & 63.16 & 36.84 & 0.00 \\
$\mathbf{1 0 . 3 2}$ & 48.65 & 19.10 & 32.25 \\
$\mathbf{1 5 . 1 6}$ & 68.31 & 28.78 & 2.91 \\
$\mathbf{1 5 . 3 2}$ & 47.37 & 38.60 & 14.03 \\
\hline
\end{tabular}


kan pada ketinggian air media $16 \mathrm{~cm}$, ikan lebih besar berpeluang untuk mendapatkan pakan karena ruang geraknya yang lebih kecil dibandingkan ketinggian air media $32 \mathrm{~cm}$. Sehingga walaupun terjadi kompetisi, efeknya tidak terlalu besar seperti pada ketinggian air media $32 \mathrm{~cm}$. Akibatnya ikan pada perlakuan ketinggian air media $16 \mathrm{~cm}$ untuk semua padat tebar ukurannya lebih kecil dibandingkan ketinggian air media $32 \mathrm{~cm}$, akan tetapi memiliki nilai sintasannya lebih besar.

Jadi untuk kegiatan produksi massal jika ingin mendapatkan sintasan yang lebih tinggi disarankan untuk melakukan sortase ukuran sebelum ikan mencapai umur dua bulan. Waktunya kira-kira pada umur satu setengah bulan yaitu pada saat mulai terjadi variasi ukuran (Gambar 1), tetapi belum sampai terjadi kematian pada ikan ukuran kecil.

\section{Pertambahan Panjang Total}

Grafik yang ditunjukkan pada Gambar 2 memperlihatkan pertambahan panjang total yang secara umum meningkat seiring meningkatnya padat tebar ikan pada ketinggian air media 16 dan $32 \mathrm{~cm}$.

Pada grafik ini pertambahan panjang total tertinggi hingga terendah secara berturutturut dihasilkan pada padat tebar larva 15, 10, dan 5 ekor/L. Sedangkan ketinggian air media yang menghasilkan pertambahan panjang total tertinggi hingga terendah diperoleh pada perlakuan ketinggian air media $32 \mathrm{~cm}$ dan $16 \mathrm{~cm}$.
Fenomena ini terjadi dikarenakan mulai dari minggu pertama hingga minggu kedua kematian larva pada padat tebar larva 15 dan 10 ekor/L untuk semua ketinggian air media mulai terjadi dan jumlahnya lebih besar dibandingkan padat tebar larva 5 ekor/L. Sehingga sintasannya menjadi kecil dan otomatis akan mengurangi jumlah padat tebar per liternya. Hal ini tentunya akan menyebabkan larva mendapatkan pakan berlebih dikarenakan jumlah pakan yang diberikan tetap, sementara jumlah ikannya berkurang. Sementara pada padat tebar larva 5 ekor/L untuk semua ketinggian air media kematian larva jumlahnya kecil sehingga padat tebarnya masih relatif tinggi. Hal ini tentunya akan memengaruhi pertambahan panjangnya. Seperti pernyataan Foss et al. (2006) yaitu ikan yang dipelihara dalam padat tebar tinggi akan berukuran lebih kecil daripada ikan yang dipelihara dalam padat tebar rendah dikarenakan ikan yang dipelihara dalam padat tebar yang sedang dan tinggi, ruang lingkup pemeliharaannya menjadi kurang berimbang. Walaupun terjadi perbedaan pertambahan panjang total akan tetapi secara statistik memperlihat perbedaan tidak signifikan.

Untuk pertumbuhan panjang total, nilai tertinggi dihasilkan oleh perlakuan padat tebar larva 15 ekor/L dengan ketinggian air media $32 \mathrm{~cm}$, perlakuan padat tebar larva 10 ekor/L dengan ketinggian air media $32 \mathrm{~cm}$ dan perlakuan padat tebar larva 15 ekor/L dengan ketinggian air media $16 \mathrm{~cm}$ dengan nilai $0,7 \pm 0,03 \mathrm{~cm} ; 0,6 \pm 0,14 \mathrm{~cm}$; dan $0,6 \pm 0,05 \mathrm{~cm}$.

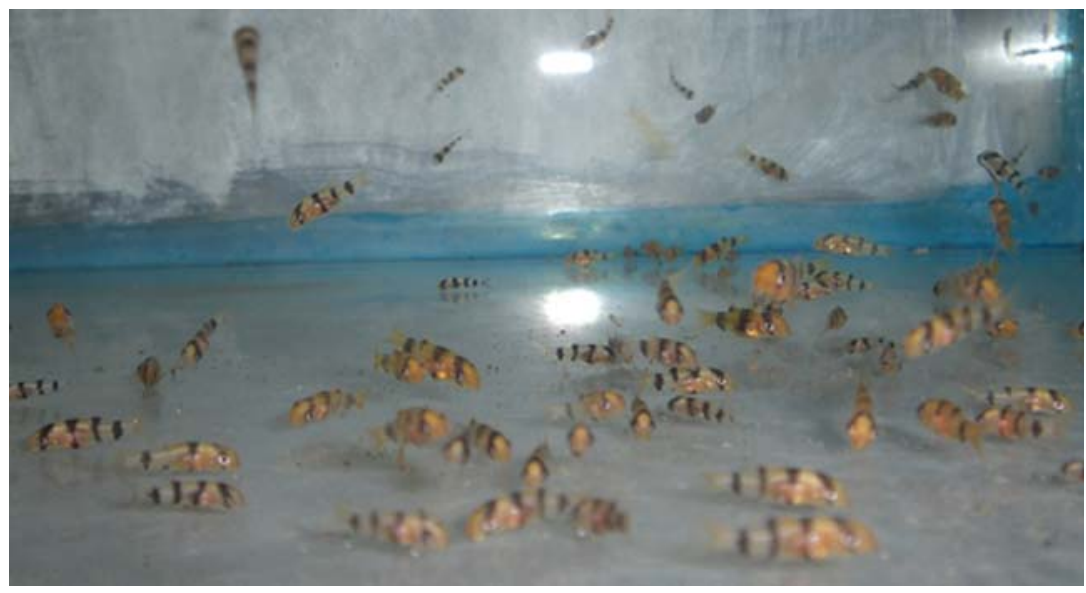

Gambar 1. Variasi ukuran benih ikan botia pada pemeliharaan di bulan kedua

Figure 1. Size variation of fish at second month rearing 


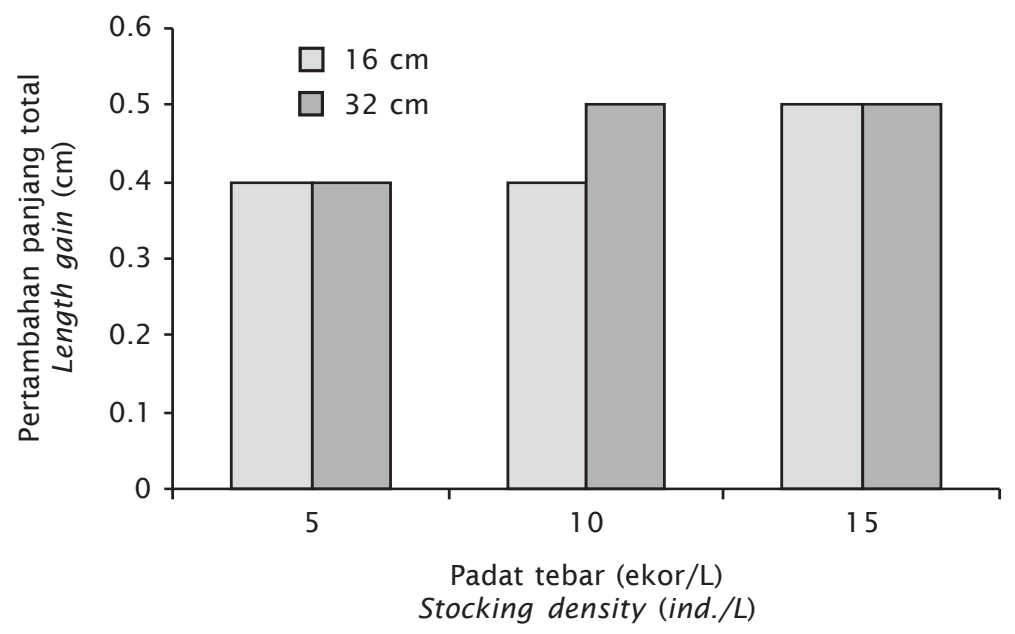

Gambar 2. Pertambahan panjang total $(\mathrm{cm})$ benih botia pada tiga padat tebar larva $(5,10,15$ ekor/L) dan dua ketinggian air media $(16,32 \mathrm{~cm})$ di bulan pertama

Figure 2. Length gain (cm) of clown loach fish fry on three stocking density (5, 10, 15 larvae/L) and two water high level (16, $32 \mathrm{~cm}$ ) until the first month

Pertumbuhan panjang total yang secara umum meningkat seiring meningkatnya padat tebar ikan. Pertumbuhan panjang total tertinggi hingga terendah secara berturut-turut dihasilkan pada perlakuan padat tebar larva 15, 10, dan 5 ekor/L. Sedangkan ketinggian air media yang menghasilkan pertumbuhan panjang total tertinggi hingga terendah diperoleh pada ketinggian $32 \mathrm{~cm}$ dan $16 \mathrm{~cm}$. Hal ini juga berlaku pada semua padat tebar larva.

Pola pertumbuhan panjang total yang terjadi pada pemeliharaan di bulan kedua mirip seperti di bulan pertama. Hal ini dikarenakan pertumbuhan panjang total akan dipengaruhi oleh padat tebar pada perlakuan tersebut. Di mana di bulan kedua ini padat tebar pada perlakuan padat tebar larva 15 dan 10 ekor/L sudah menurun dibanding perlakuan padat tebar larva 5 ekor/L akibat adanya kematian yang terjadi di bulan pertama. Terjadi perbedaan pertumbuhan panjang total, tapi secara statistik perbedaan ini tidak signifikan atau tidak berbeda nyata.

\section{Pertumbuhan Bobot Mutlak}

Grafik yang ditunjukkan pada Gambar 3 memperlihatkan pertumbuhan bobot mutlak yang secara umum meningkat seiring mening- katnya padat tebar ikan pada semua ketinggian air media walaupun terjadi pengecualian pada perlakuan padat tebar larva 10 ekor/L dengan ketinggian air media $32 \mathrm{~cm}$ di mana nilainya lebih tinggi dibanding perlakuan padat tebar larva 15 ekor/L dengan ketinggian air media $32 \mathrm{~cm}$.

Pada grafik ini pertumbuhan bobot mutlak tertinggi hingga terendah secara berturut turut dihasilkan pada padat tebar larva 15, 10 , dan 5 ekor/L. Sedangkan pada perlakuan ketinggian air media yang menghasilkan pertumbuhan bobot mutlak tertinggi hingga terendah diperoleh pada perlakuan ketinggian air media $32 \mathrm{~cm}$ dan diikuti ketinggian air media $16 \mathrm{~cm}$.

Fenomena ini hampir sama seperti pada pertumbuhan panjang total, hal ini terjadi dikarenakan mulai dari minggu pertama hingga minggu kedua kematian larva pada padat tebar larva 15 dan 10 ekor/L untuk semua ketinggian air media mulai terjadi dan jumlahnya lebih besar dibandingkan padat tebar larva 5 ekor/L. Sehingga sintasannya menjadi kecil dan otomatis akan mengurangi jumlah padat tebar per liternya. Hal ini tentunya akan menyebabkan larva mendapatkan pakan berlebih dikarenakan jumlah pakan yang diberikan tetap, sementara jumlah ikannya 


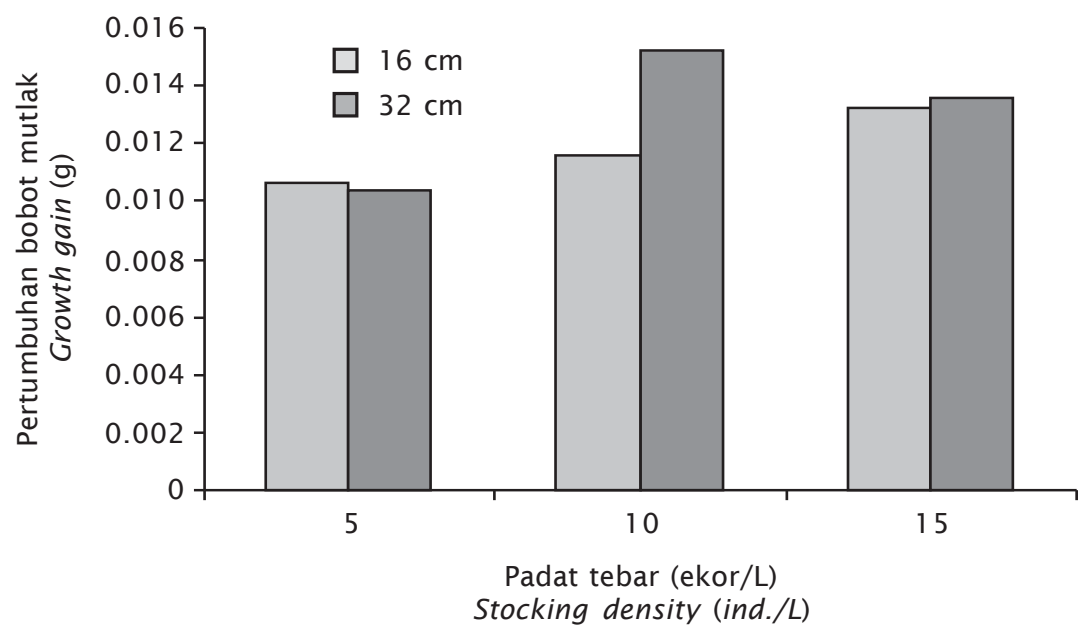

Gambar 3. Pertumbuhan bobot mutlak (g) benih botia pada tiga padat tebar larva $(5,10,15$ ekor/L) dan dua ketinggian air media $(16,32 \mathrm{~cm})$ di bulan pertama

Figure 3. Growth gain $(\mathrm{cm})$ of clown loach fish fry on three stocking density $(5,10,15$ larvae/L) and two water high level $(16,32 \mathrm{~cm})$ until the first month

berkurang. Sementara pada padat tebar larva 5 ekor/L pada semua ketinggian air media kematian larva jumlahnya kecil sehingga padat tebarnya masih relatif tinggi. Hal ini tentunya akan memengaruhi pertumbuhan bobotnya. Akan tetapi walaupun terjadi perbedaan pertumbuhan bobot mutlak tapi secara statistik perbedaan ini tidak signifikan atau tidak berbeda nyata. Sedangkan untuk pertumbuhan bobot mutlak nilai tertinggi didapat oleh perlakuan padat tebar larva 10 ekor/L dengan ketinggian air media $32 \mathrm{~cm}$ dan perlakuan padat tebar larva 15 ekor/L dengan ketinggian air media $32 \mathrm{~cm}$ dengan nilai $0,0343 \pm 0,0161 \mathrm{~g}$ dan 0,0332 $\pm 0,0323 \mathrm{~g}$.

Pertumbuhan bobot mutlak yang secara umum meningkat seiring meningkatnya padat tebar ikan walaupun terjadi pengecualian pada perlakuan padat tebar larva 10 ekor/L dengan ketinggian air media $32 \mathrm{~cm}$ di mana nilainya lebih tinggi dibanding perlakuan padat tebar larva 15 ekor/L dengan ketinggian air media $32 \mathrm{~cm}$. Pertumbuhan bobot mutlak tertinggi hingga terendah secara berturut-turut dihasilkan pada perlakuan padat tebar 15, 10, dan 5 ekor/L. Sedangkan ketinggian air media yang menghasilkan pertumbuhan bobot mutlak tertinggi hingga terendah diperoleh pada ketinggian air media $32 \mathrm{~cm}$ dan $16 \mathrm{~cm}$. Hal ini juga berlaku pada semua padat tebar.
Pola pertumbuhan bobot mutlak yang terjadi pada pemeliharaan di bulan kedua mirip seperti pada bulan pertama. Hal ini dikarenakan pertumbuhan bobot mutlak akan dipengaruhi oleh padat tebar pada perlakuan tersebut. Di mana di bulan kedua ini kepadatan pada perlakuan padat tebar larva 15 dan 10 ekor/L sudah menurun dibanding perlakuan padat tebar 5 ekor/L akibat adanya kematian yang terjadi di bulan pertama. Terjadi perbedaan pertumbuhan bobot mutlak, tetapi secara statistik perbedaan ini tidak signifikan atau tidak berbeda nyata.

\section{Kualitas Air}

Selama penelitian dilakukan pengukuran data kualitas air, sebagai upaya monitoring kondisi air sebagai media pemeliharaan larva. Data kualitas air selama penelitian tertera pada Tabel 4.

Data kualitas air media selama penelitian untuk setiap perlakuan berada dalam batas toleransi untuk kehidupan larva hingga benih ikan botia tersebut. Menurut Mills \& Lamnert (2004), bahwa kisaran suhu air media yang baik bagi kehidupan ikan daerah tropis yaitu $25^{\circ} \mathrm{C}$ $32^{\circ} \mathrm{C}$. Sedangkan $\mathrm{pH}, \mathrm{DO}$, nitrit, dan ammonia berada dalam kisaran yang baik untuk ikan botia (Satyani et al., 2007). 


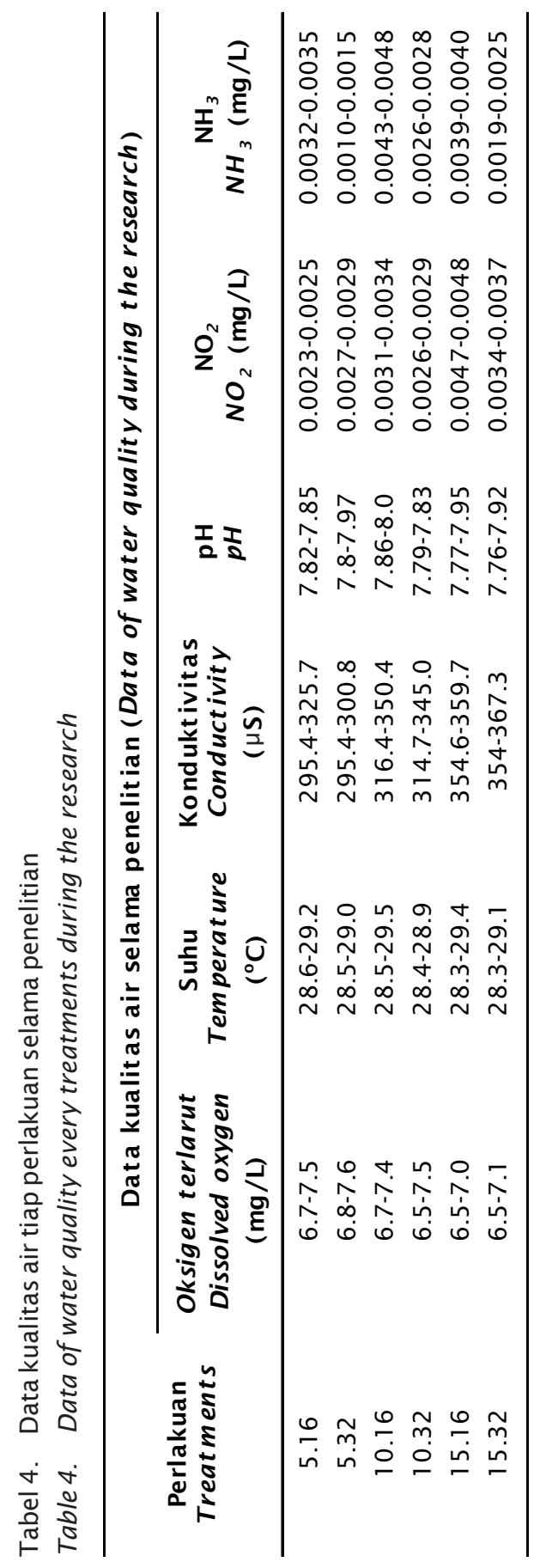


Melihat dari tujuan penelitian ini yaitu ingin mendapatkan nilai sintasan yang optimal dengan pendekatan padat tebar dan ketinggian air media memang harus juga memperhatikan batasan sampai sejauh mana peningkatan padat tebar ini menghasilkan sintasan yang optimal tetapi kualitas air tetap terkontrol. Hal ini sesuai dengan pendapat Baras (2009), yaitu upaya untuk dapat meningkatkan sintasan larva botia, selain memperhatikan faktor padat tebar juga harus memperhatikan kualitas air media pemeliharaan.

\section{KESIMPULAN}

Padat tebar larva dan ketinggian air media dalam pemeliharaan larva botia hingga benih selama 2 bulan berpengaruh nyata terhadap sintasan dan tidak berpengaruh nyata terhadap pertambahan panjang total dan bobot mutlak. Perlakuan dengan padat tebar larva 15 ekor/L dengan ketinggian air media pemeliharaan $16 \mathrm{~cm}$ dapat direkomendasikan dalam kegiatan produksi massal benih selama 2 bulan pemeliharaan.

\section{SARAN}

Wajib dilakukan sortase/sortir ukuran ikan pada umur 40-45 hari untuk mencegah terjadinya kematian yang tinggi karena perbedaan ukuran dan dapat meningkatkan sintasannya.

\section{DAFTAR ACUAN}

Baras, E. 2009. Research on Clown Loach (Chromobotia macracanthus). Synthetic Report. Annual Report of Freshwater Fish Diversity in South East Asia: "FISH-DIVA". Institut de Recherche pour le Développement (IRD) dan Badan Riset Kelautan Perikanan (BRKP), $36 \mathrm{hlm}$.

Effendie, I. 1979. Metode Biologi Perikanan. Yayasan Dewi Sri, Bogor, $112 \mathrm{hlm}$.

Effendie, I. 2004. Pengantar Akuakultur. Penebar Swadaya, Jakarta, $184 \mathrm{hlm}$.

Foss, A., Kristensen, T., Atland, A., Hustveit, H., Hovland, Øfsti, A., \& Imsland, A.K. 2006. Effects of water reuse and stocking density on water quality, blood physiology and growth rate of juvenile cod (Gadus morhua). Aquaculture, 256: 255-263.

Helfman, G.S., Collette, B.B., \& Facey, D.E. 1997. The diversity of fishes. Blackwell science, USA, $528 \mathrm{pp}$.

Huet, M. 1994. Textbook of fish culture: breeding and cultivation of fish ( $2^{\text {nd }}$ edition). Fishing News Books, Cambridge, 438 pp.

Kristikareni, R.D. 2009. Pengaruh Padat Penebaran Terhadap Kelangsungan Hidup Larva Botia Dalam Sistem Resirkulasi. Skripsi. Fakultas Perikanan dan Ilmu Kelautan. Universitas Padjadjaran. Jatinangor, $65 \mathrm{hlm}$.

Mills, D. \& Lamnert, D. 2004. The Aquarium Fish Handbook. Grange Books. United Kingdom, $256 \mathrm{pp}$.

North, B.P., Ellis, T., Turnbull, J.F., Davis, J., \& Bromage, N.R. 2006. Stocking density practices of commercial UK rainbow trout farms. Aquaculture, 259: 260-267.

Odum, E.P. 1993. Dasar-Dasar Ekologi. Edisi ketiga. Gajah Mada University Press. Yogyakarta, hlm. 134-162.

Paspatis, M., Batarias, C., Tiangos, P., \& Kentouri, M. 1999. Feeding and growth in response of sea bass (Dicentrarchus labrax) reared by four feeding methods. Aquaculture, 175: 293-305.

Rowland, S.J., Mifsuda, C., Nixon, M., \& Boyd, P. 2006. Effects of stocking density on the performance of the Australian freshwater silver perch (Bidyanus bidyanus) in cages. Aquaculture, 253: 301-308.

Satyani, D., Mundriyanto, H., Subandiyah, S., Chumaidi, Sudarto, Taupik, P., Slembrouck, J., Legendre, M., \& Pouyoud, L. 2007. Teknologi Pembenihan Ikan Hias Botia (Chromobotia macracanthus Bleeker). Loka Riset Budidaya Ikan Hias air Tawar, Depok, Jawa Barat, $23 \mathrm{hlm}$.

Weatherley, L.A. 1972. Growth and ecology of fish population. Academic press. Inc., London, $293 \mathrm{p}$.

Wedemeyer, G.A. 1996. Physiology of Fish in Intensive Culture Systems. Chapman and Hall, Melbourne, 232 pp. 